\title{
Endurance shuttle walking test: responsiveness to salmeterol in COPD
}

\author{
C. Brouillard*, V. Pepin ${ }^{\#}$, J. Milot*, Y. Lacasse* and F. Maltais*
}

ABSTRACT: Few studies have shown that the endurance shuttle walking test (ESWT) is responsive to treatment in patients with chronic obstructive pulmonary disease (COPD). This exercise test needs to be further investigated because of its relevance for activity of daily living. The aim of the present study was to evaluate, in patients with COPD, the responsiveness of the ESWT in detecting improvement in walking performance after a single dose of salmeterol.

In a randomised, double-blind, placebo-controlled crossover trial, 20 patients with COPD performed two ESWT at $80 \%$ of peak capacity $2.5 \mathrm{~h}$ after inhaling either a placebo or $50 \mu \mathrm{g}$ of salmeterol. Cardiorespiratory parameters were monitored during each walking test. Inspiratory capacities and Borg ratings for dyspnoea were obtained every other minute throughout the tests.

Compared with placebo, salmeterol produced a significant change in lung function and a significant improvement in walking performance (mean \pm SD difference in time: $117 \pm 20 \mathrm{~s}$; difference in distance: $160 \pm 277 \mathrm{~m}$ ). At isotime (the latest exercise time that was reached on both ESWT), a significant reduction in dyspnoea was observed after bronchodilation.

Bronchodilation with salmeterol reduced dyspnoea during walking and improved walking capacity in patients with chronic obstructive pulmonary disease. These findings provide further support for the use of the endurance shuttle walking test as an evaluative tool in chronic obstructive pulmonary disease.

KEYWORDS: Bronchodilators, chronic obstructive pulmonary disease, endurance, exercise capacity, exercise testing, salmeterol

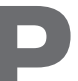
atients with chronic obstructive pulmonary disease (COPD) complain of premature exertional dyspnoea and leg fatigue [1] and exercise intolerance mainly due to a reduced ventilatory capacity, impaired gas exchange and peripheral muscle dysfunction. While short-acting bronchodilators may be sufficient for handling symptoms in the early phases of the disease process, long-acting bronchodilators are typically better suited to treating patients with more advanced disease $[2,3]$.

Long-acting bronchodilators, such as salmeterol and tiotropium, have been shown to improve dyspnoea and quality of life and to reduce exacerbations in patients with COPD [4-6]. In well-designed, randomised, placebo-controlled clinical trials, these two bronchodilators have also been convincingly shown to improve the endurance time to submaximal cycling exercise in this patient population [7-9]. This benefit can be shown in the few hours following the administration of the first dose of the medication $[7,8]$. For a given exercise stimulus, long-acting $\beta_{2}$-agonists and anticholinergics also reduce the perception of dyspnoea [8,9].
Although the symptomatic and functional benefit associated with these drugs is felt to be clinically relevant, it is not known whether the observed improvement in cycling capacity would translate into better performances in different activities of daily living, such as walking. To date, clinical trials assessing the impact of salmeterol on walking performance in COPD patients have led to disappointing results $[6,10,11]$. However, these trials used the 6-min walking test (6MWT), a test recently shown to lack sensitivity to bronchodilation $[12,13]$. Thus, it is possible that the impact of salmeterol on walking performance was underestimated by these clinical trials.

Recently, the endurance shuttle walking test (ESWT), an externally paced field walking test, was found to be responsive to bronchodilation and rehabilitation [13-15]. The present investigation was therefore undertaken to test, in patients with COPD, the hypothesis that the ESWT is responsive in detecting improvement in walking capacity following a single dose of salmeterol. More specifically, the objectives of the study were: 1) to measure the acute changes in walking performance induced by a single dose of

\section{AFFILIATIONS}

${ }^{*}$ Centre of research, Hôpital Laval, Institut Universitaire de Cardiologie et de Pneumologie de l'Université Laval, Quebec City, QC, and ${ }^{*}$ Centre de recherche, Hôpital du Sacré-Coeur de Montreal, Montreal, QC, Canada.

CORRESPONDENCE

F. Maltais

Centre de Pneumologie

Hôpital Laval

2725 Chemin Ste-Foy

Quebec

QC

G1V 4G5

Canada

Fax: 14186564762

E-mail: francois.maltais@

med.ulaval.ca

Received:

September 072007

Accepted after revision:

November 142007

\section{SUPPORT STATEMENT}

V. Pepin and F. Maltais are research scholars of the Fonds de la Recherche en Santé du Québec (Quebec, Canada). The study's registration number at ClinicalTrials.gov is NCT0052564

\section{STATEMENT OF INTEREST}

Statements of interest for J. Milot and F. Maltais, and the study itself can be found at www.erj.ersjournals.com/ misc/statements.shtm 
salmeterol against those induced by a placebo; and 2) to evaluate the physiological (minute ventilation $\left(V^{\prime} \mathrm{E}\right)$, oxygen uptake $\left(V^{\prime} \mathrm{O}_{2}\right)$, carbon dioxide production $\left(V^{\prime} \mathrm{CO}_{2}\right)$, cardiac frequency $(f C)$ and inspiratory capacity) and symptomatic (dyspnoea) responses during each walking test to provide a mechanistic explanation of the findings.

\section{METHODS}

\section{Subjects}

Patients with clinically stable COPD participated in the study. Inclusion criteria were as follows: 1) age $\geqslant 50 \mathrm{yrs} ; 2$ ) current or past smoking history of $\geqslant 10$ pack-yrs; 3) forced expiratory volume in one second (FEV1) $\leqslant 70 \%$ of the predicted value; 4 ) FEV1/forced vital capacity (FVC) $\leqslant 70 \% ; 5)$ no acute COPD exacerbation within the preceding 2 months; 6) no history of asthma; 7) no significant arterial oxygen desaturation $(<85 \%)$ at rest or during exercise; and 8) no other active condition that could influence exercise tolerance. Patients on long-acting anticholinergics were excluded from the study due to the long wash-out period required for this medication. No participant was involved in pulmonary rehabilitation in the previous year. The research protocol was approved by the Institutional Ethics Committee (Hôpital Laval, Quebec City, QC, Canada) and a signed, informed consent was obtained from each subject.

\section{Study design}

The study required five visits to the research facility. Each visit was separated by $\geqslant 48 \mathrm{~h}$ and $\leqslant 4$ days. The first visit included a baseline assessment of pulmonary function and an incremental shuttle walking test (ISWT). The following two visits (visits 2 and 3) were used to familiarise participants to the ESWT. The goal of the familiarisation was to reduce the learning effect that typically occurs when an individual completes the same endurance test several times [8]. Patients whose ESWT at visit 2 and 3 were not reproducible (when the difference in endurance time between visit 2 and 3 was $>2 \mathrm{~min}$ ) or longer than $20 \mathrm{~min}$ were excluded. For the remaining two visits (visits 4 and 5), subjects entered a crossover design where they completed one ESWT at each visit, $150 \pm 15 \mathrm{~min}$ after the inhalation of $50 \mu \mathrm{g}$ of salmeterol or the inhalation of a placebo. Pulmonary function tests were performed before (pre-dose) and $120 \pm 20 \mathrm{~min}$ after (post-dose) the inhalation of the placebo or salmeterol. The medication was administered in a randomised and double-blind fashion using the Diskus ${ }_{\circledR}$ (GlaxoSmithKline, Ware, UK) device, which was identical in appearance between placebo and active medication. Treatment sequence was determined using a random number table.

All visits were conducted at the same time of the day for each subject. Subjects remained on their usual medication between visits. Short-acting $\beta_{2}$-agonists and short-acting anticholinergics were stopped $6 \mathrm{~h}$ preceding visits $2-5$, while theophyllines and long-acting $\beta_{2}$-agonists were stopped $48 \mathrm{~h}$ before visits 4 and 5 . Inhaled salbutamol (short-acting $\beta_{2}$-agonist) was used as rescue medication when subjects had to stop their medication for $48 \mathrm{~h}$. Finally, subjects were asked to avoid smoking, caffeine, dark chocolate, cola beverages, heavy meals, alcohol and major physical exertion prior to visits because these factors can influence exercise performance.

\section{Pulmonary function testing}

Standard pulmonary function tests, including spirometry, lung volumes and diffusing capacity of the lung for carbon monoxide were measured according to previously described guidelines [16]. Results were compared with predicted normal values from the European Community for Coal and Steel/ European Respiratory Society [17]. Maximum voluntary ventilation was estimated by multiplying FEV1 by 35 [18].

\section{Incremental walking exercise test}

Peak walking capacity was determined with the ISWT [19], which was performed in an enclosed corridor on a flat $10 \mathrm{~m}$ long course. The course was identified by two cones, each positioned $0.5 \mathrm{~m}$ from either end to allow patients to walk in a circle and thereby avoid the need for abrupt changes in direction. Patients had to follow the rhythm dictated by the audio signal. Walking speed was initially set at $0.5 \mathrm{~m} \cdot \mathrm{s}^{-1}$ and subsequently increased by $0.17 \mathrm{~m} \cdot \mathrm{s}^{-1}$ every minute until the patient reached a symptom-limited maximum. Encouragement was provided during the test and patients received standardised instructions to walk for as long as possible.

\section{Endurance walking exercise test}

Endurance walking capacity was determined with the ESWT. The ESWT was performed on the same course as the ISWT in accordance with published guidelines [20]. After $1.5 \mathrm{~min}$ of warm up, walking speed was set at the speed corresponding to $80 \%$ of peak $V^{\prime} \mathrm{O}_{2}$, as predicted from the ISWT [20]. Before each ESWT, patients received standardised instructions to walk for as long as possible, although there was a predetermined 20min maximum. No encouragement was provided during these tests to avoid any potential confounding effect on exercise performance [21]. Reproducibility criteria were set at $\leqslant 2 \mathrm{~min}$ or $10 \%$ between consecutive ESWT.

\section{Physiological measures}

During each exercise test, gas exchange parameters $\left(V^{\prime} \mathrm{O}_{2}\right.$, $V^{\prime} \mathrm{CO}_{2}, V^{\prime} \mathrm{E}$ and arterial oxygen saturation measured by pulse oximetry), respiratory frequency $(f \mathrm{R})$, tidal volume $(V \mathrm{~T})$ and $f C$ were monitored breath by breath with a portable telemetric system (Oxycon Mobile; Viasys Healthcare GmbH, Hoechberg, Germany). This system is both light (950 g including belt, battery and mask) and compact, and consists of a facemask, $f C$ monitor, battery, transmitting unit (containing the $\mathrm{O}_{2}$ and $\mathrm{CO}_{2}$ gas analysers) and receiving unit. The volume sensor and gas analysers were calibrated before each test. Patients were asked to perform inspiratory capacity manoeuvres at 2-min intervals during the exercise period. This was carried out to follow changes in operational lung volumes occurring during exercise, as described previously [22]. When end-expiratory volume was stable, as indicated by real-time flow-volume loops, subjects were asked, at the end of a normal expiration, to take a deep inspiration to total lung capacity.

\section{Subjective measures}

Dyspnoea and perception of leg fatigue were evaluated at rest and at end exercise using the modified 10-point Borg scale [23]. Dyspnoea was also evaluated at 2-min intervals during the exercise tests. At the end of each test, patients were asked to identify the main reason for which they stopped the test. 


\section{Statistical analysis}

Results are reported as mean $\pm \mathrm{SD}$, unless otherwise stated. The level of significance of $\alpha=0.05$ was used for all analyses. The endurance time was defined as the duration of walking at $80 \%$ maximum capacity, excluding the 1.5-min warm-up period. Comparisons of the values observed with salmeterol and placebo were made using a $2 \times 2$ crossover design in which the period, sequence and treatment effects were considered. In order to study possible determinants of the improved walking capacity after bronchodilation, multiple regression analysis was performed using the changes in walking endurance time as the dependant variable and the post-bronchodilator changes in FEV1, FVC, functional residual capacity, inspiratory capacity and dyspnoea at isotime during exercise as independant variables. Isotime was defined as the latest exercise time that was reached on both ESWT. The sample size calculation was based on the assumption that the improvement in the walking endurance time with salmeterol should be at least of similar magnitude to that of ipratropium bromide (164 $\pm 177 \mathrm{~s})$ [14]. It was calculated that 20 patients would be needed to complete the study with a power of 0.85 and a type-I error of 0.05 .

\section{RESULTS}

\section{Subjects}

The study flow chart is presented in figure 1 . In total, 28 patients initially volunteered to participate in the study but only 20 patients were actually randomised at visit 4 and received the study medication. These patients all completed the study. The following results pertain to this population. Subject characteristics are presented in table 1 . Of the study group, 30\% were females. Patients had, on average, moderate-to-severe airflow obstruction with mild hyperinflation and gas trapping at rest.

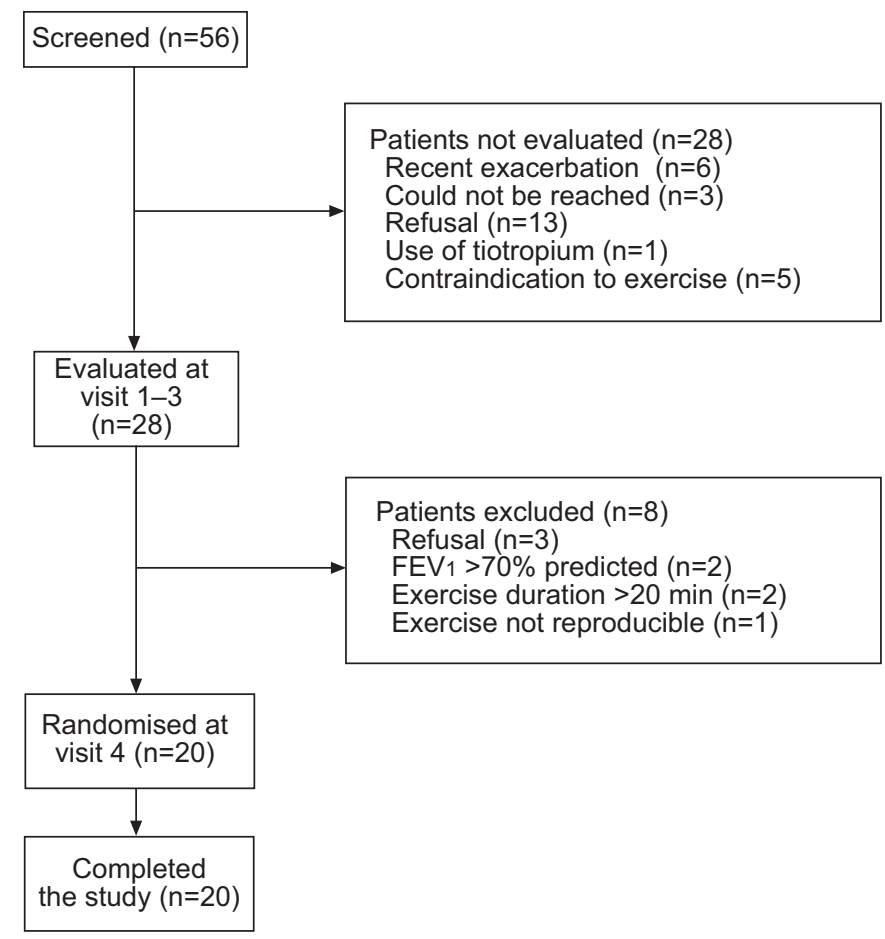

FIGURE 1. Flow chart of the study. FEV 1 : forced expiratory volume in one second

\section{Pulmonary function}

Pre- and post-dose pulmonary function measurements are shown in table 2. Significant drug effects were found after treatment with salmeterol compared with placebo. The preand post-bronchodilator improvements in FEV1 and FVC and reduction in residual volume were significantly larger for salmeterol compared with placebo (table 2).

\section{Endurance time and walking distance}

No sequence or carry-over effect was observed in the present investigation. There was a significant improvement in walking performance (difference in endurance time salmeterol-placebo: $117 \pm 208 \mathrm{~s} ; \mathrm{p}=0.02$ ) and walking distance (difference in walking distance salmeterol-placebo: $160 \pm 277 \mathrm{~m}$; $\mathrm{p}=0.02$ ) with salmeterol inhalation. Individual data for changes in endurance time from the placebo to the salmeterol condition for the ESWT are shown in figure 2. In multiple regression analysis, the change in Borg at isotime and post-bronchodilator increase in FVC explained $71 \%$ of the variance in the endurance time with bronchodilation. The post-bronchodilator changes in FEV1 or inspiratory capacity did not improve the ability to predict the changes in endurance time in the multiple regression analysis.

\section{Physiological response}

Time course and end-exercise values for dyspnoea under the placebo and salmeterol conditions are shown in figure 3. Salmeterol significantly reduced dyspnoea at isotime (difference in dyspnoea salmeterol-placebo: $-0.60 \pm 1.10 ; \mathrm{p}=0.006)$, as

TABLE 1 Subject characteristics and data at peak exercise

\begin{tabular}{|c|c|c|}
\hline & Value & $\%$ predicted \\
\hline Subjects & 20 & \\
\hline Females & $6(30)$ & \\
\hline Age yrs & $65 \pm 6$ & \\
\hline$B M I \mathbf{k g} \cdot \mathrm{m}^{-2}$ & $26.9 \pm 4.7$ & \\
\hline FEV 1 L & $1.38 \pm 0.55$ & $52 \pm 15$ \\
\hline FVC L & $3.27 \pm 1.23$ & $95 \pm 19$ \\
\hline FEV $_{1 / \text { FVC } \%}$ & $43 \pm 10$ & \\
\hline TLC L & $6.42 \pm 1.79$ & $108 \pm 15$ \\
\hline IC L & $2.34 \pm 0.77$ & $88 \pm 20$ \\
\hline FRC L & $4.07 \pm 1.33$ & $125 \pm 30$ \\
\hline RV L & $3.02 \pm 0.86$ & $134 \pm 33$ \\
\hline $\mathrm{Sp}, \mathrm{O}_{2} \%$ rest & $94.8 \pm 4.1$ & \\
\hline DL,CO \% pred & & $61 \pm 15$ \\
\hline Peak $V^{\prime} \mathrm{O}_{2} \mathrm{~mL} \cdot \mathbf{k g}^{-1} \cdot \mathrm{min}^{-1}$ & $18.5 \pm 3.6$ & \\
\hline Peak $V^{\prime} \mathrm{O}_{2} L \cdot \min ^{-1}$ & $1.4 \pm 0.4$ & \\
\hline Peak V'E L·min ${ }^{-1}$ & $49.4 \pm 16.8$ & \\
\hline$V^{\prime} E / M V V$ peak \% & $97.7 \pm 15.0$ & \\
\hline Peak $f c$ beats $\mathrm{min}^{-1}$ & $133 \pm 15$ & \\
\hline \multicolumn{3}{|c|}{$\begin{array}{l}\text { Data are presented as } n, n(\%) \text { and mean } \pm S D \text {. BMI: body mass index; FEV1: } \\
\text { forced expiratory volume in one second; } F V C \text { : forced vital capacity; TLC: total } \\
\text { lung capacity; IC: inspiratory capacity; } F R C \text { : functional residual capacity; RV: } \\
\text { residual volume; } S p, \mathrm{O}_{2} \text { : pulse oxygen saturation; } D L, C O \text { : diffusing capacity of the } \\
\text { lung for carbon monoxide; } V^{\prime} \mathrm{O}_{2} \text { : oxygen uptake; } V^{\prime} E \text { : minute ventilation; } M V V \text { : } \\
\text { maximum voluntary ventilation; } f C \text { : cardiac frequency. }\end{array}$} \\
\hline
\end{tabular}


TABLE 2 Pre- and post-dose pulmonary function measurements

\begin{tabular}{|c|c|c|c|c|c|}
\hline & \multicolumn{2}{|c|}{ Placebo } & \multicolumn{2}{|c|}{ Salmeterol } & \multirow{2}{*}{$\begin{array}{c}\Delta \text { Salmeterol (post-pre)- } \Delta \text { placebo } \\
\text { (post-pre) }\end{array}$} \\
\hline & Pre & Post & Pre & Post & \\
\hline FEV 1 L & $1.24 \pm 0.49$ & $1.19 \pm 0.50$ & $1.21 \pm 0.45$ & $1.31 \pm 0.51$ & $0.15 \pm 0.08^{\#}$ \\
\hline FVC L & $3.10 \pm 1.06$ & $3.02 \pm 1.14$ & $3.07 \pm 1.04$ & $3.22 \pm 1.08$ & $0.23 \pm 0.18^{\#}$ \\
\hline FRC L & $4.31 \pm 1.19$ & $4.22 \pm 1.24$ & $4.21 \pm 1.09$ & $4.04 \pm 1.15$ & $-0.07 \pm 0.33$ \\
\hline IC L & $2.14 \pm 0.68$ & $2.13 \pm 0.74$ & $2.21 \pm 0.73$ & $2.27 \pm 0.76$ & $0.07 \pm 0.27$ \\
\hline
\end{tabular}

Data are presented as mean \pm SD. FEV1: forced expiratory volume in one second; FVC: forced vital capacity; FRC: functional residual capacity; TLC: total lung capacity; RV: residual volume; IC: inspiratory capacity. *: $p<0.05$; ${ }^{*}: p<0.0001$

shown in table 3 and figure 3. The cardiorespiratory response to ESWT was similar between the placebo and salmeterol conditions. Interestingly, patients were able to reach greater $V \mathrm{~T}$ $(0.04 \pm 0.08 \mathrm{~L} ; \mathrm{p}=0.005)$ at end exercise after salmeterol. Endexercise dyspnoea was similar between the two conditions. Inspiratory capacity measurement while walking was challenging and some patients were unable to perform the manoeuvres. In others, a drift in the end expiratory lung volume was observed, preventing reliable estimation of inspiratory capacity. In the eight out of 20 patients in whom this procedure was completed, inspiratory capacity at isotime was $220 \mathrm{~mL}$ greater with salmeterol compared with placebo $(p=0.07)$.

\section{Locus of symptom limitation}

The perception of dyspnoea and leg fatigue at end exercise was not significantly altered by salmeterol. During the salmeterol condition, 12 patients $(60 \%)$ cited dyspnoea as the main limiting factor, whereas four $(20 \%)$ cited leg fatigue and four (20\%) the combination of both symptoms. For the placebo condition, 14 patients (70\%) cited dyspnoea, two (10\%) leg fatigue and four $(20 \%)$ the combination of both symptoms.

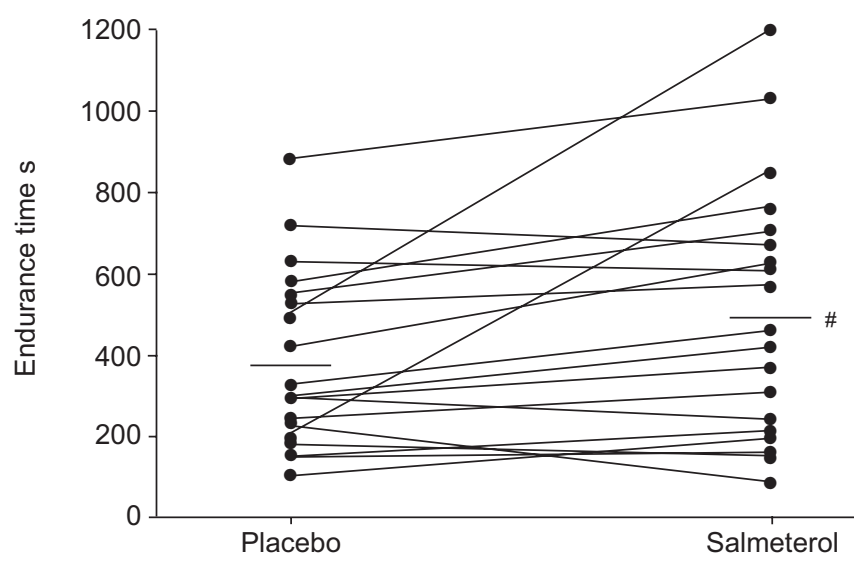

FIGURE 2. Individual data for changes in endurance time from the placebo to the salmeterol condition for the endurance shuttle walking test. The group mean for each experimental condition is represented by the horizontal bars. ${ }^{\#}$ : end exercise endurance time $p=0.02$.

\section{DISCUSSION}

The major finding of the present study was that the ESWT enabled the detection of functional changes after bronchodilation in patients with COPD. In addition to the improvement in walking endurance time with salmeterol, a reduction in dyspnoea at a given exercise time and a tendency toward reduced dynamic hyperinflation during walking were also observed.

There is growing interest in demonstrating the efficacy of bronchodilation on functional status in patients with COPD [79]. To this end, the utility and responsiveness of constant workrate cycling exercise to pharmacotherapy have been confirmed in large clinical trials [7-9]. Despite providing convincing physiological evidence of the efficacy of bronchodilation in patients with COPD, the clinical relevance of these findings may be questioned since cycling is not a typical activity of daily living in patients with COPD [24]. Walking would appear an obvious alternative to cycling in order to address the limitation of cycling-based indices of exercise capacity. Although the initial experience with the 6MWT to evaluate the effects of bronchodilation was disappointing [12], PEPIN and co-workers $[13,14]$ have reported more encouraging results using the ESWT. In these investigations, the ESWT has proved to be sensitive to acute bronchodilation and more responsive to this intervention than the $6 \mathrm{MWT}[13,14]$. The current state of knowledge about the efficacy of salmeterol in improving walking capacity is consistent with these notions. Three previous investigations reported that salmeterol did not improve 6-min walking distance, casting doubt on the efficacy of this medication in improving functional status $[6,10,11]$. In contrast, by using a walking protocol with better evaluative properties than the $6 \mathrm{MWT}$, the present investigation confirms that a long-acting $\beta_{2}$-agonist may improve walking capacity in patients with COPD. This indicates that the evaluative properties of a given exercise test have to be considered when designing clinical trials.

The ESWT was initially developed as a simple field exercise test for the measurement of response to therapy in patients with COPD [20]. The use of portable technology, now allowing a detailed physiological evaluation during walking and the assessment of dyspnoea perception, makes it possible to explore possible mechanisms of improvement in walking 


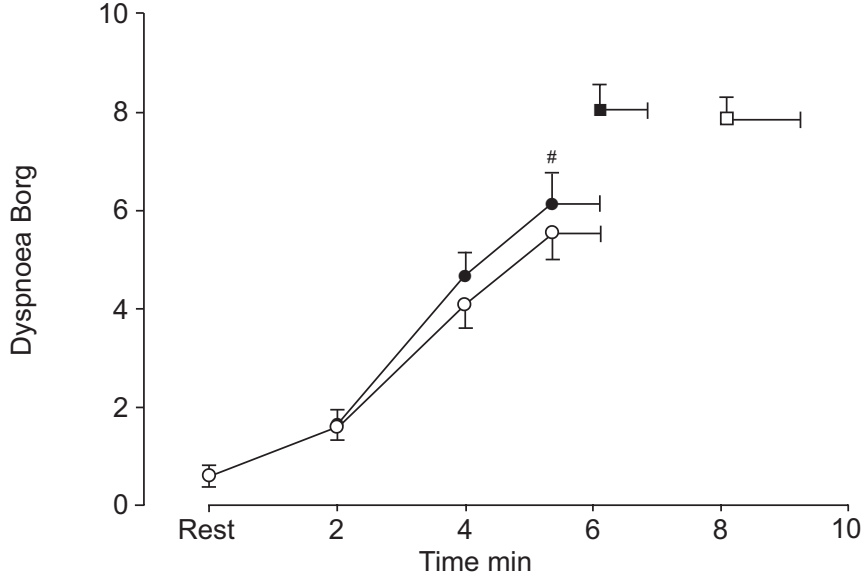

FIGURE 3. Time course ( $\bullet$ and $\bigcirc$ ) and peak end exercise values ( $\square$ and $\square$ ) for dyspnoea under the placebo ( $\bullet$ and $\boldsymbol{\square}$ ) and salmeterol ( $\bigcirc$ and $\square$ ) conditions for the endurance shuttle walking test. At 4 min, dyspnoea scores were available for 19 out of 20 patients. There was a significant reduction in dyspnoea at isotime. Data are presented as mean \pm SD. ${ }^{\#}: \mathrm{p}=0.006$.

capacity as it is often carried out during cycling [7-9]. The changes in breathing pattern with slower $f R$ and larger $V \mathrm{~T}$ were small but consistent in magnitude with previous reports [7-9]. An interesting novelty of the present investigation was the possibility of performing, in a subset of patients, repeated measurements of inspiratory capacity while they were actually walking in the corridor and of monitoring the degree of dynamic hyperinflation occurring during walking exercise. The magnitude of improvement in inspiratory capacity with bronchodilation was consistent with previous clinical trials [79]. Reduced perception of dyspnoea at isotime with bronchodilation together with the improvement in FVC, a reflection of more complete lung emptying and reduced gas trapping, were important determinants of the improvement in endurance time, as indicated by the multiple regression analysis.

The present study confirms that the ESWT, in conjunction with a portable exercise circuit, is an appropriate exercise modality for the assessment of the functional and physiological responses to bronchodilation. An interesting feature of walking is that it induces less leg fatigue compared with other exercise modalities, such as cycling [14, 25]. This could be important given that the occurrence of leg fatigue during exercise may prevent bronchodilation from fully translating into better exercise capacity [26]. Indeed, in patients predominantly limited by quadriceps muscle fatigue during cycling, the administration of a bronchodilator has been shown not to translate into improvements in exercise tolerance [26]. Other advantages of the ESWT include the fact that it may show, more consistently than cycling, the functional gain associated with bronchodilation [14] and that it is relevant for daily living.

Nevertheless, it is important to appreciate the potential shortcomings of walking as an evaluating exercise modality. Inspiratory capacity and dyspnoea are more difficult to assess during free walking compared with during stationary cycling. Also, the pattern of lower limb muscles recruitment is not as

\begin{tabular}{|c|c|c|c|c|}
\hline \multirow[t]{3}{*}{ TABLE 3} & $\begin{array}{l}\text { rcise ar } \\
\text { urance }\end{array}$ & $\begin{array}{l}\text { isotime } \\
\text { uttle walk }\end{array}$ & $\begin{array}{l}\text { asurem } \\
\text { test }\end{array}$ & ts during \\
\hline & \multicolumn{2}{|c|}{ End exercise } & \multicolumn{2}{|c|}{ Isotime } \\
\hline & Placebo & Salmeterol & Placebo & Salmeterol \\
\hline Exercise time $\mathbf{s}$ & $373 \pm 216$ & $490 \pm 312^{\circ}$ & $358 \pm 221$ & $358 \pm 221$ \\
\hline Distance $\mathrm{m}$ & $512 \pm 353$ & $672 \pm 478^{\circ}$ & & \\
\hline Dyspnoea Borg & $8.1 \pm 2.2$ & $7.9 \pm 2.0$ & $6.2 \pm 2.6$ & $5.6 \pm 2.5^{+}$ \\
\hline Leg discomfort Borg & $5.6 \pm 2.6$ & $5.6 \pm 3.1$ & & \\
\hline$V^{\prime} \mathrm{O}_{2} \mathbf{m} \cdot \mathbf{k g}^{-1} \cdot \mathrm{min}^{-1}$ & $18.2 \pm 3.1$ & $18.0 \pm 3.3$ & $18.1 \pm 3.2$ & $17.7 \pm 3.0$ \\
\hline$V^{\prime} \mathrm{O}_{2} L \cdot \min ^{-1}$ & $1.4 \pm 0.3$ & $1.4 \pm 0.3$ & $1.4 \pm 0.3$ & $1.3 \pm 0.3$ \\
\hline$V^{\prime} \mathrm{CO}_{2} L \cdot \min ^{-1}$ & $1.3 \pm 0.4$ & $1.3 \pm 0.4$ & $1.3 \pm 0.4$ & $1.3 \pm 0.4$ \\
\hline$V^{\prime} E L \cdot \min ^{-1}$ & $45.6 \pm 15.7$ & $47.2 \pm 16.2$ & $45.3 \pm 15.8$ & $45.7 \pm 13.9$ \\
\hline$V^{\prime} E / M^{\prime} V^{\#} \%$ & $103.6 \pm 16.0$ & $107.1 \pm 18.5$ & & \\
\hline RER & $0.98 \pm 0.13$ & $0.98 \pm 0.11$ & $0.97 \pm 0.12$ & $0.97 \pm 0.11$ \\
\hline fR breaths $\cdot \mathrm{min}^{-1}$ & $35.8 \pm 5.9$ & $36.1 \pm 6.3$ & $35.6 \pm 6.2$ & $34.8 \pm 5.5$ \\
\hline VT L & $1.27 \pm 0.37$ & $1.31 \pm 0.39^{\S}$ & $1.27 \pm 0.36$ & $1.32 \pm 0.39$ \\
\hline IC L & $1.86 \pm 0.58$ & $1.83 \pm 0.63$ & $1.93 \pm 0.60$ & $2.15 \pm 0.75^{f}$ \\
\hline fc beats $\mathrm{min}^{-1}$ & $129 \pm 12$ & $131 \pm 11$ & $128 \pm 13$ & $127 \pm 11$ \\
\hline $\mathrm{Sp}, \mathrm{O}_{2} \%$ & $89.5 \pm 7.4$ & $90.2 \pm 6.2$ & $90.1 \pm 6.5$ & $90.8 \pm 5.9$ \\
\hline
\end{tabular}

Data are presented as mean $\pm \mathrm{SD}$. $V^{\prime} \mathrm{O}_{2}$ : oxygen uptake; $V^{\prime} \mathrm{CO}_{2}$ : carbon dioxide output; V'E: minute ventilation; MVV: maximum voluntary ventilation; RER respiratory exchange ratio; $f R$ : respiratory frequency; $V T$ : tidal volume; IC inspiratory capacity; $\mathrm{fC}$ : cardiac frequency; $\mathrm{Sp}_{1} \mathrm{O}_{2}$ : pulse oxygen saturation \# : MVV was calculated from the post-bronchodilator forced expiratory volume in one second value obtained at the placebo visit; $\because p=0.02 ;{ }^{+}: p=0.006$ §. $\mathrm{p}=0.005 ;{ }^{f}$ : due to technical reasons, IC data are only available for eight out of 20 patients $(p=0.07)$.

well controlled during walking than cycling. For instance, stride length and strategies during turning, which may influence the metabolic requirements, cannot be easily controlled from one walking test to the other. Despite this, walking appears to be a promising strategy for future clinical trials aiming to evaluate the impact of pharmacotherapy on functional status in patients with COPD. In the absence of a minimal clinically important difference for the ESWT, the significance of changes observed with treatment is difficult to interpret. Preliminary results from the current authors' laboratory indicate that an 85-s improvement in ESWT is likely to be perceived positively by patients [27]. As such, it is possible that the average gain in walking endurance obtained with salmeterol was not only statistically significant but also clinically meaningful. Further investigation is necessary to better appreciate the clinical significance of the gain in walking capacity reported in the present study.

In conclusion, the present study demonstrates the ability of salmeterol to improve walking capacity in patients with chronic obstructive pulmonary disease. The study extends the results of previous investigations about the evaluative properties of the endurance shuttle walking test in patients with chronic obstructive pulmonary disease. This exercise modality can be used to assess endurance to constant work rate walking exercise. Detailed physiological evaluation can also be obtained during free walking when coupled with a portable exercise circuit. 


\section{ACKNOWLEDGEMENTS}

The authors acknowledge the help of M. Bélanger, M-J. Breton, B. Jean and J. Picard in performing the study and É. Nadreau (all Centre de Recherche, Hôpital Laval, Institut Universitaire de Cardiologie et de Pneumologie de l'Université Laval, Quebec City, QC, Canada) for technical assistance. They also thank G. Daigle (Université Laval, Quebec City) for statistical assistance.

\section{REFERENCES}

1 Hamilton AL, Killian KJ, Summers E, Jones NL. Muscle strength, symptom intensity and exercise capacity in patients with cardiorespiratory disorders. Am J Respir Crit Care Med 1995; 152: 2021-2031.

2 Global Initiative for Chronic Obstructive Lung Disease. Global Strategy for the Diagnosis, Management, and Prevention of Chronic Obstructive Pulmonary Disease. 2005. www.goldcopd.com Date last accessed: January 8, 2008. Date last updated: December 2007.

3 O'Donnell DE, Aaron S, Bourbeau J, et al. Canadian Thoracic Society recommendations for management of chronic obstructive pulmonary disease: 2007 update. Can Respir J 2007; 14: Suppl. B, 5B-32B.

4 Dahl R, Greefhorst LAPM, Nowak D, et al. Inhaled formoterol dry powder versus ipratropium bromide in chronic obstructive pulmonary disease. Am J Respir Crit Care Med 2001; 164: 778-784.

5 Jones PW, Bosh TK. Quality of life changes in COPD patients treated with salmeterol. Am J Respir Crit Care Med 1997; 155: 1283-1289.

6 Mahler DA, Donohue JF, Barbee RA, et al. Efficacy of salmeterol xinafoate in the treatment of COPD. Chest 1999; 115: 957-965.

7 Maltais F, Hamilton A, Marciniuck D, et al. Improvements in symptom-limited exercise performance over eight hours with once-daily tiotropium in patients with COPD. Chest 2005; 128: 1168-1178.

8 O'Donnell DE, Fluge T, Gerken F, et al. Effects of tiotropium on lung hyperinflation, dyspnoea and exercise tolerance in COPD. Eur Respir J 2004; 23: 832-840.

9 O'Donnell DE, Voduc N, Fitzpatrick M, Webb KA. Effect of salmeterol on the ventilatory response to exercise in chronic obstructive pulmonary disease. Eur Respir J 2004; 24: 86-94.

10 Boyd G, Morice AH, Pounsford JC, Siebert M, Peslis N, Crawford C. An evaluation of salmeterol in the treatment of chronic obstructive pulmonary disease (COPD). Eur Respir J 1997; 10: 815-821.

11 Grove A, Lipworth BJ, Reid P, et al. Effects of regular salmeterol on lung function and exercise capacity in patients with chronic obstructive airways disease. Thorax 1996; 51: 689-693.

12 Oga T, Nishimura K, Tsukino M, Hajiro T, Ikeda A, Izumi T. The effects of oxitropium bromide on exercise performance in patients with stable chronic obstructive pulmonary disease. A comparison of three different exercise tests. Am J Respir Crit Care Med 2000; 161: 1897-1901.
13 Pepin V, Brodeur J, Lacasse Y, et al. Six-minute walking versus shuttle walking: responsiveness to bronchodilation in chronic obstructive pulmonary disease. Thorax 2007; 63: 291-298.

14 Pepin V, Saey D, Whittom F, LeBlanc P, Maltais F. Walking versus cycling: sensitivity to bronchodilation in chronic obstructive pulmonary disease. Am J Respir Crit Care Med 2005; 172: 1517-1522.

15 Eaton T, Young P, Nicol K, Kolbe J. The endurance shuttle walking test: a responsive measure in pulmonary rehabilitation for COPD patients. Chron Respir Dis 2006; 3: 3-9.

16 American Thoracic Society. Standards for the diagnosis and care of patients with chronic obstructive pulmonary disease (COPD) and asthma. Am Rev Respir Dis 1987; 136: 225-244.

17 Quanjer PH, Tammeling GJ, Cotes JE, Pedersen OF, Peslin R, Yernault JC. Lung volumes and forced ventilatory flows. Report Working Party Standardization of Lung Function Tests, European Community for Steel and Coal. Official Statement of the European Respiratory Society. Eur Respir J 1993; 6: Suppl. 16, 5-40.

18 Clark TJH, Freedman S, Campbell EJM, Winn R. The ventilatory capacity of patients with chronic airway obstruction. Clin Sci 1969; 36: 307-316.

19 Singh SJ, Morgan MD, Scott S, Walters D, Hardman AE. Development of a shuttle walking test of disability in patients with chronic airways obstruction. Thorax 1992; 47: 1019-1024.

20 Revill SM, Morgan MD, Singh SJ, Williams J, Hardman AE. The endurance shuttle walk: a new field test for the assessment of endurance capacity in chronic obstructive pulmonary disease. Thorax 1999; 54: 213-222.

21 Guyatt GH, Pugsley S, Sullivan MJ, et al. Effect of encouragement on walking test performance. Thorax 1984; 39: 818-822.

22 O'Donnell DE, Lam M, Webb KA. Measurement of symptoms, lung hyperinflation, and endurance during exercise in chronic obstructive pulmonary disease. Am J Respir Crit Care Med 1998; 158: 1557-1565.

23 Borg G. Psychophysical bases of perceived exertion. Med Sci Sports Exer 1982; 14: 377-381.

24 Pitta F, Troosters T, Spruit MA, Probst VS, Decramer M, Gosselink R. Characteristics of physical activities in daily life in chronic obstructive pulmonary disease. Am J Respir Crit Care Med 2005; 171: 972-977.

25 Man WD, Soliman MG, Gearing J, et al. Symptoms and quadriceps fatigability after walking and cycling in chronic obstructive pulmonary disease. Am J Respir Crit Care Med 2003; 168: 562-567.

26 Saey D, Debigaré R, LeBlanc $\mathrm{P}$, et al. Contractile leg fatigue after cycle exercise: a factor limiting exercise in patients with COPD. Am J Respir Crit Care Med 2003; 168: 425-430.

27 Brouillard C, Pepin V, Singh S, Revill SM, Lacasse Y, Maltais F. Interpreting changes in endurance shuttle walking performance. Am J Respir Crit Care Med 2007; 175: A367. 